Article

\title{
The Influence of Light Irradiation on the Photocatalytic Degradation of Organic Pollutants
}

\author{
Alexandru Enesca * and Luminita Isac (D) \\ Product Design, Mechatronics and Environmental Department, Transilvania University of Brasov, \\ Eroilor 29 Street, 35000 Brasov, Romania; isac.luminita@unitbv.ro \\ * Correspondence: aenesca@unitbv.ro; Tel.: +40-268413000
}

Received: 30 April 2020; Accepted: 27 May 2020; Published: 29 May 2020

check for updates

\begin{abstract}
The design of a photocatalytic process must consider intrinsic and extrinsic parameters affecting its overall efficiency. This study aims to outline the importance of balancing several factors, such as radiation source, total irradiance, photon flux, catalyst substrate, and pollutant type in order to optimize the photocatalytic efficiency. Titanium oxide was deposed by the doctor blade technique on three substrates (microscopic glass (G), flour-doped tin oxide (FTO), and aluminum $(\mathrm{Al})$ ), and the photocatalytic properties of the samples were tested on two pollutants (tartrazine (Tr) and acetamiprid (Apd)). Seven irradiation scenarios were tested using different ratios of UV-A, UV-B $+\mathrm{C}$, and Vis radiations. The results indicated that the presence of a conductive substrate and a suitable ratio of UV-A and Vis radiations could increase the photocatalytic efficiency of the samples. Higher efficiencies were obtained for the sample Ti_FTO (58.3\% for Tr and 70.8\% for Apd) and the sample Ti_Al (63.8\% for Tr and $82.3 \%$ for Apd) using a mixture of three UV-A and one Vis sources $\left(13.5 \mathrm{~W} / \mathrm{m}^{2}\right.$ and $\left.41.85 \mu \mathrm{mol} /\left(\mathrm{m}^{2} \cdot \mathrm{s}\right)\right)$. A kinetic evaluation revealed two different mechanisms of reaction: (a) a one-interval mechanism related to Apd removal by Ti_FTO, Ti_Al (scenarios 1, 4, 5, and 7), and Ti_G samples (scenario 7) and (b) a two-interval mechanism in all other cases.
\end{abstract}

Keywords: $\mathrm{TiO}_{2}$; doctor blade; photocatalysis; light spectra; photon flux; kinetics

\section{Introduction}

Sustainability is a key parameter to be considered when designing environmental treatment processes for pollutant removal from wastewater, air, or soil. The light absorption range is an important factor that directly influences the photocatalytic activity of a semiconductor. Therefore, the influence of the irradiation light on the photocatalytic performance of various semiconductors must be studied because it can provide a basis for a further understanding of the photocatalysis principles. Additionally, there must be a balance between energy consumption and photocatalytic efficiency in order to properly design a photocatalytic technology [1-3].

Advanced oxidation processes (AOPs) based on semiconductor photocatalysts are recognized to remove, through mineralization, organic pollutants in low concentrations, including emergent organic dyes [4,5], pesticides [6,7], pharmaceutical compounds [8,9], etc. The economic factor is usually considered very relevant, as AOPs are energy-intensive [10,11], especially due to the most commonly employed UV activation [12-14]. Until now, many papers have reported the use of AOPs especially based on composites [15,16], semiconductors [17-19], or hybrid systems [20,21]. It is known that photocatalysis aims at the use of light radiation, with infield radiation values of hundreds of $\mathrm{W} / \mathrm{m}^{2}$. Based on practical reasons, most laboratory-scale experiments are developed at lower or even different irradiance values. Consequently, it is difficult to compare results when the kinetics of the photocatalytic process is influenced by the input radiation. 
This paper presents several parameters that should be considered when designing a photocatalytic experiment: irradiation sources, total irradiance, photon flux, catalyst substrate, and pollutant type. Three types of substrate were used for $\mathrm{TiO}_{2}$ deposition by the doctor blade technique: microscopic glass (G), flour-doped tin oxide (FTO), and aluminum. During the photocatalytic experiments, the influence of UV-A, UV-B + C, and Vis radiations (in various ratios) was investigated for two types of pollutants: a dye (tartrazine) and a pesticide (acetamiprid). The study includes an evaluation of the kinetic mechanism based on the influence of the photon flux corresponding to each irradiation scenarios.

\section{Materials and Methods}

\subsection{Photocatalyst Materials}

Three samples were prepared based on $\mathrm{TiO}_{2}$ Degussa P25 powder as follows:

1. Sample Ti_G: a $\mathrm{TiO}_{2}$ film was deposed on a microscopic glass substrate by the doctor blade technique. Previously, the substrate was degreased with surfactants and cleaned by successive immersion in acetone and ethanol for 15 min using an ultrasound bath. After deposition, the samples where thermally treated at $500{ }^{\circ} \mathrm{C}$ for $6 \mathrm{~h}$.

2. Sample Ti_FTO: a $\mathrm{TiO}_{2}$ film was deposed on a flour-doped tin oxide substrate by the doctor blade technique; similar cleaning and thermal procedures as for Ti_G were used.

3. Sample Ti_Al: a $\mathrm{TiO}_{2}$ film was deposed on an aluminum substrate by the doctor blade technique.

Previously, the substrate was degreased with surfactants, cleaned with ethanol, polished, and dried at room temperature. A thin layer of $\mathrm{Al}_{2} \mathrm{O}_{3}$ was developed on the surface of the aluminum substrate using an electrochemical setup consisting of a platinum cathode, an aluminum anode, and $25 \% \mathrm{H}_{2} \mathrm{SO}_{4}$ as the electrolyte. The technological parameters were voltage $12.6 \mathrm{~V}$, current $1 \mathrm{~A} / \mathrm{dm}^{2}$ for $30 \mathrm{~min}$. The samples were cleaned again in ethanol after the electrochemical process. The post-deposition thermal treatment was done at $200{ }^{\circ} \mathrm{C}$ for $6 \mathrm{~h}$.

A paste was obtained by dispersing $0.5 \mathrm{~g} \mathrm{TiO}_{2}$ Degussa P25 powder into solutions containing ethanol, acetylacetonate, and Triton X100 in a volumetric ratio of 10:1:1. The samples' size was identical $\left(1.5 \times 2.5 \mathrm{~cm}^{2}\right)$, and the same deposition procedure was used to obtain the $\mathrm{TiO}_{2}$ film.

\subsection{Photocatalytic Experiments}

A photocatalytic reactor was designed to accomplish several conditions: (1) uniform light intensity distribution using 4 light sources, (2) low-humidity environment, and (3) stable environmental temperature (between 20 and $25^{\circ} \mathrm{C}$ ). Several light scenarios where used as presented in Table 1 . The UV irradiation sources were black light tubes (F18W/T8, UVA, typically $340-400 \mathrm{~nm}$, with $\lambda_{\mathrm{UVA}, \max }=365 \mathrm{~nm}$, flux intensity 3Lx, Philips, New York, NY, USA), fluorescent tubes (T38 TL 20W/12, UVB + C, typically 210-310 nm, with $\lambda_{\mathrm{UVB}}+\mathrm{C}, \max =295 \mathrm{~nm}$, flux intensity 2.4Lx, Philips, New York, NY, USA), and Vis white cold light tubes (TL-D Super $8018 \mathrm{~W} / 865$, typically $400-700 \mathrm{~nm}$, with $\lambda_{\mathrm{Vis}, \max }=565 \mathrm{~nm}$, flux intensity 28Lx, Philips, New York, NY, USA).

Table 1. Irradiation scenarios parameters.

\begin{tabular}{ccccc}
\hline Irradiation Scenarios & UV-A Sources & UV-B + C Sources & Vis Sources & Total Irradiance $\left(\mathbf{W} / \mathbf{m}^{\mathbf{2}}\right)$ \\
\hline Scenario 1 & 4 & 0 & 0 & 12.3 \\
Scenario 2 & 0 & 4 & 0 & 8.6 \\
Scenario 3 & 0 & 0 & 4 & 17.6 \\
Scenario 4 & 2 & 2 & 0 & 10.1 \\
Scenario 5 & 2 & 0 & 2 & 14.8 \\
Scenario 6 & 0 & 2 & 2 & 12.9 \\
Scenario 7 & 3 & 0 & 1 & 13.5 \\
\hline
\end{tabular}


Each irradiation scenario was applied to all samples using two reference pollutants, i.e., the dye tartrazine (Tr) and the pesticide acetamiprid (Apd). Each sample was immersed in $30 \mathrm{~mL}$ of pollutant solution $(0.025 \mathrm{mM})$ for $10 \mathrm{~h}$. In the first $2 \mathrm{~h}$, the samples were kept in the dark in order to reach absorption equilibrium. During the following $8 \mathrm{~h}$, the samples were irradiated using one of the scenarios presented in Table 1 . The variation in concentration was evaluated based on the UV-Vis calibration curve and hourly measured, up to $8 \mathrm{~h}$ of photo-catalysis. Consequently, of the total experiment period of $10 \mathrm{~h}, 2 \mathrm{~h}$ where without irradiation and $8 \mathrm{~h}$ with irradiation.

The photocatalytic efficiency was evaluated using Equation (1):

$$
\eta=\left[\frac{\left(C_{0}-C\right)}{C_{0}}\right] \times 100,
$$

where $C_{0}$ represents the initial concentration, and $C$ represents the pollutant concentration at moment $t$.

\subsection{Investigation Instruments}

The crystalline structure was investigated using X-ray diffraction (XRD, Bruker D8 Discover Diffractometer (Karlsruhe, Germany), the locked-couple technique with 0.002-degree scan step and $0.01 \mathrm{~s} / \mathrm{step}$ ). The samples' morphology was evaluated using scanning electron microscopy (SEM, Hitachi model S-3400 N type 121 II, Fukuoka, Japan) in a high vacuum regime. A UV-Vis spectrometer (Perkin Elmer Lambda 950, Waltham, MA, USA) was used to monitor the photocatalytic activity and to evaluate the photocatalytic kinetics. Total irradiance values were measured in the central position of the sample holder, using a class A pyranometer (SR11, Hukseflux, Berlin, Germany).

\section{Results and Discussions}

\subsection{Crystalline Structure and Morphology}

The presence of a crystalline structure is considered as prerequisite in photocatalytic applications due to the importance of charge carriers (electrons and holes) for the development of oxidative species. It is well known that $\mathrm{TiO}_{2}$ anatase is the most photoactive structure in the photocatalytic degradation of organic pollutants [22,23]. However, Scanlon et al. [24] showed that using both rutile and anatas crystalline, $\mathrm{TiO}_{2}$ structures will promote photon conversion based on the effective band gap shift toward Vis radiation (up to $2.81 \mathrm{eV}$ ). Diffraction analysis (see Figure 1) showed that all samples contained both anatase and rutile $\mathrm{TiO}_{2}$ structures, and no additional peaks corresponding to other $\mathrm{TiO}_{2}$ structures were detected. The sample Ti_FTO exhibited $\mathrm{SnO}_{2}$ tetragonal structure peaks characteristic of the conductive FTO layer, which could interfere with the charge carrier mobility during the photocatalytic activity. Additional $\mathrm{Al}_{2} \mathrm{O}_{3}$ peaks were present for the Ti_Al sample as a consequence of the anodization process.

The morphology was investigated by scanning electron microscopy in semi-vacuum without metallic coverage, and the results are presented in Figure 2. Due to the doctor blade deposition process characteristics which induce the formation of thick layers and the high-temperature thermal treatment required to eliminate the organic materials, the samples presented large uniformly distributed fractures. Several papers [25-27] have shown that these fractures can act as high-energy active sites during the photocatalytic activity, which is an interface-dependent process. Smaller fractures were present in the Ti_Al sample, for which the thermal treatment was kept at $200^{\circ} \mathrm{C}$, a temperature significantly lower compared to that of the other two samples $\left(500^{\circ} \mathrm{C}\right.$ as annealing temperature). 


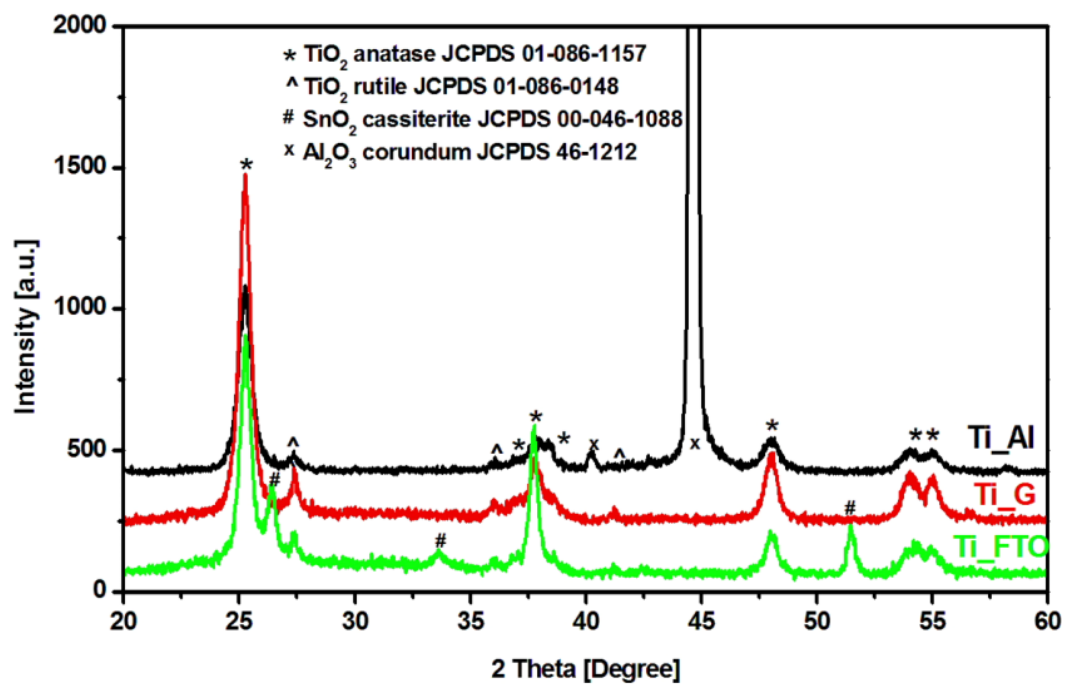

Figure 1. X-Ray diffraction pattern corresponding to $\mathrm{Ti} \_\mathrm{Al}\left(\mathrm{TiO}_{2}\right.$ film on an aluminum substrate), Ti_G ( $\mathrm{TiO}_{2}$ film on a microscopic glass substrate), and $\mathrm{Ti}$ FTO $\left(\mathrm{TiO}_{2}\right.$ film on a flour-doped tin oxide substrate) samples.

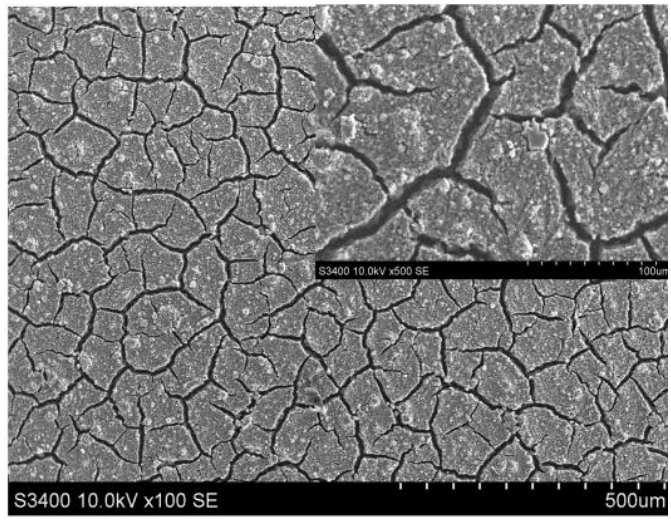

(a)

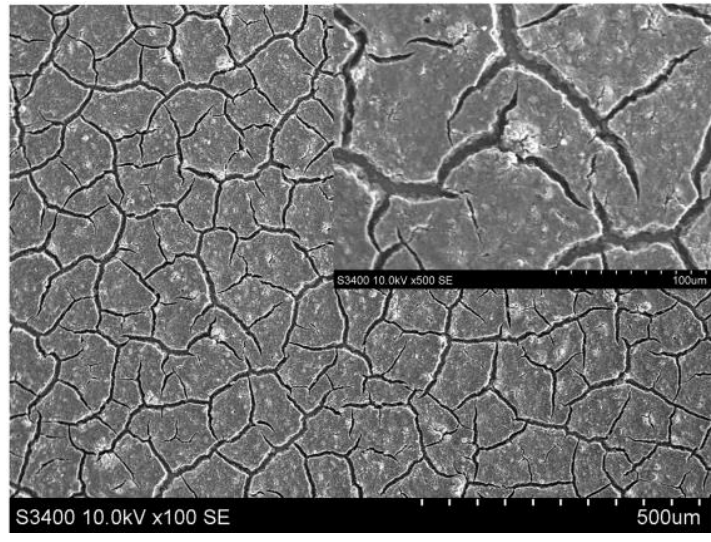

(b)

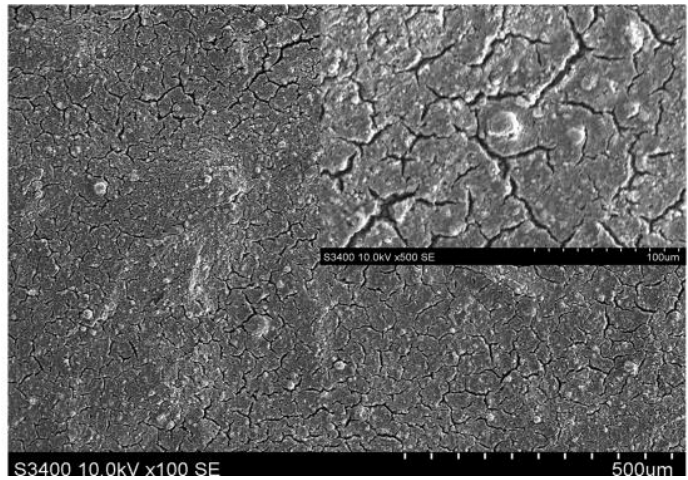

(c)

Figure 2. SEM images corresponding to (a) Ti_G sample annealed at $500{ }^{\circ} \mathrm{C}$; (b) Ti_FTO sample annealed at $500{ }^{\circ} \mathrm{C}$, and (c) Ti_Al sample annealed at $200{ }^{\circ} \mathrm{C}$ (inset shows SEM images at higher resolution corresponding to the same samples in the respective images). 


\subsection{Photocatalytic Properties}

The influence of the different radiation schemes on the photocatalytic properties of the Ti_G sample regarding the degradation of $\operatorname{Tr}$ and Apd are presented in Figure 3a,b. Higher photocatalytic efficiency was observed for Apd in comparison to Tr. When $\operatorname{Tr}$ was used as a pollutant molecule, the available photon flux to the photocatalyst surface decreased, because light penetration through dye solutions is low [28,29]. The highest efficiencies (50.3\% for Apd and $46.6 \%$ for Tr) correspond to scenario 7, which used three UV-A and one Vis sources. Figure 3 c shows that the photocatalytic efficiency was dependent not only on total irradiation but also on the irradiation source. Similar low efficiencies were obtained at $8.6,12.9$, and $17.6 \mathrm{~W} / \mathrm{m}^{2}$, while higher efficiencies corresponded to 12.3 and $12.9 \mathrm{~W} / \mathrm{m}^{2}$. These results can be explained by the conversion of the total irradiance into a photon flux that was involved in the photocatalytic processes (see Table 2).

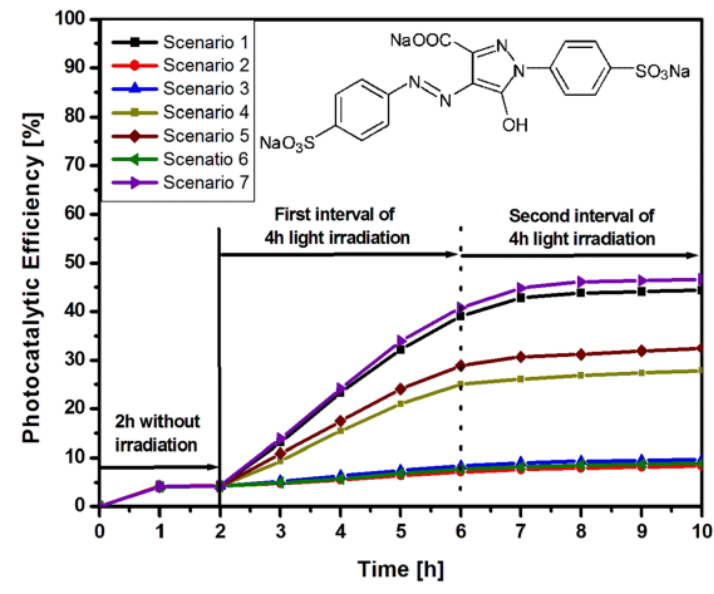

(a)

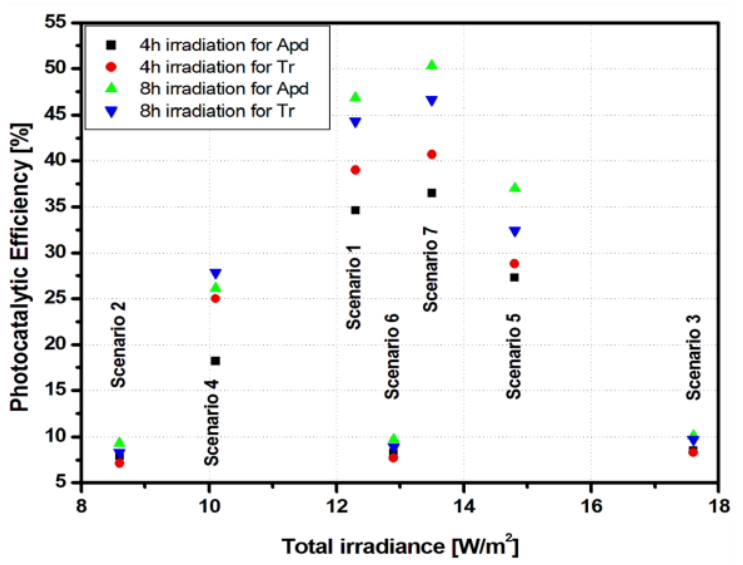

(c)

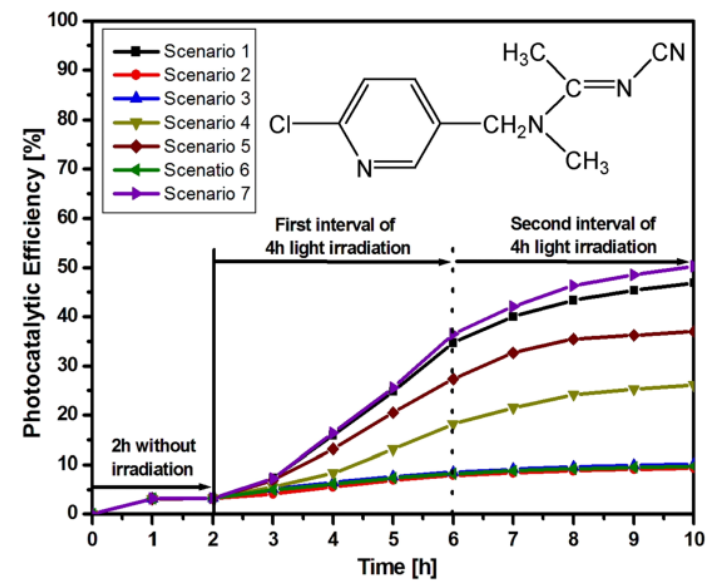

(b)

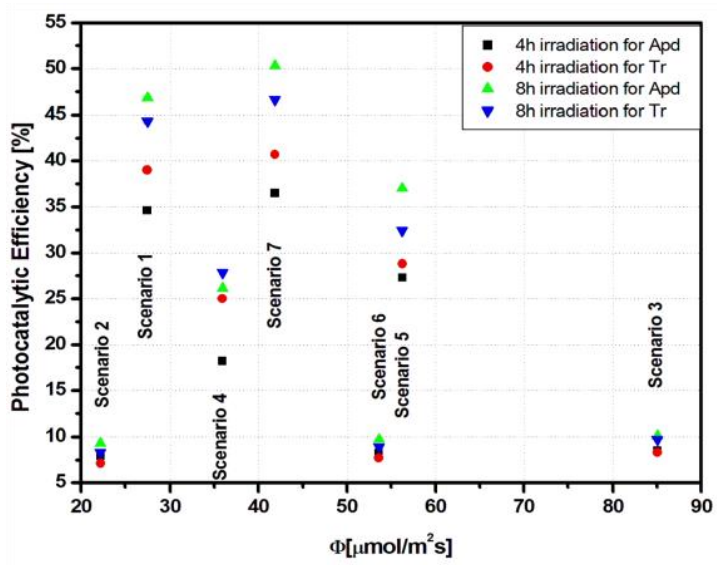

(d)

Figure 3. Photocatalytic parameters of the Ti_G sample: (a) tartrazine (Tr) photodegradation; (b) acetamiprid (Apd) photodegradation; (c) total irradiance vs. photocatalytic efficiency, and (d) photon flux vs. photocatalytic efficiency. 
Table 2. Share of UV and Vis radiation and photon flux.

\begin{tabular}{|c|c|c|c|c|}
\hline \multirow{2}{*}{ Irradiation Scenarios } & \multicolumn{2}{|c|}{ UV (\%) } & \multirow{2}{*}{ Vis $(\%)$} & \multirow{2}{*}{$\Phi\left(\mu \mathrm{mol} /\left(\mathrm{m}^{2} \cdot \mathrm{s}\right)\right)$} \\
\hline & A & $B+C$ & & \\
\hline Scenario 1 & 100 & 0 & 0 & 27.46 \\
\hline Scenario 2 & 0 & 100 & 0 & 22.20 \\
\hline Scenario 3 & 0 & 0 & 100 & 85.02 \\
\hline Scenario 4 & 60 & 40 & 0 & 35.93 \\
\hline Scenario 5 & 40.5 & 0 & 59.5 & 56.24 \\
\hline Scenario 6 & 0 & 31 & 69 & 53.61 \\
\hline Scenario 7 & 67.5 & 0 & 32.5 & 41.85 \\
\hline
\end{tabular}

On average, the irradiance values corresponding to one single irradiation source were: $\mathrm{E}_{\mathrm{UVA}}=3.1 \mathrm{~W} / \mathrm{m}^{2}$ for the UV-A source(s), $\mathrm{E}_{\mathrm{UVB}+\mathrm{C}}=2.15 \mathrm{~W} / \mathrm{m}^{2}$ for the UV-B $+\mathrm{C}$ source $(\mathrm{s}), \mathrm{E}_{\mathrm{Vis}}=4.4 \mathrm{~W} / \mathrm{m}^{2}$ for the Vis source(s). Based on these values, on the number of sources ( $n_{u v}$ and, respectively $\left.n_{v i s}\right)$, and on the maximum wavelength of the sources $\left(\lambda_{U V}, \max , \lambda_{V i s, \max }\right)$, the maximum photon flux reaching the quartz beaker during each experimental trial, $\Phi$, was calculated using Equation (2), [30]:

$$
\Phi=\frac{E_{\mathrm{UV}} \times \lambda_{\mathrm{UV}} \times \mathrm{n}_{\mathrm{UV}}+\mathrm{E}_{\mathrm{Vis}} \times \lambda_{\mathrm{Vis}} \times \mathrm{n}_{\mathrm{Vis}}}{\mathrm{h} \times \mathrm{c} \times \mathrm{N}_{\mathrm{Av}}},
$$

where the Planck constant (h), the speed of light (c), and the Avogadro number have the usual values.

The efficiencies for scenarios 1 and 7 were similar even if the photon flux (Figure 3d) was almost double. This is an indicator showing that increasing the photon flux is not enough if there is no correspondence with the photocatalyst effective band gap. Literature data $[31,32]$ mention that the energy corresponding to the effective band gap is the one that has to be surpassed for photo-activation, which, in the case of Degussa $\mathrm{TiO}_{2}$ (containing both anatase and rutile structures), is $2.81 \mathrm{eV}$.

A similar behavior was observed for samples Ti_FTO and Ti_Al. However, in comparison with Ti_G, the other two samples showed better photocatalytic efficiency for both $\operatorname{Tr}$ (Figures 4a and 5a) and Apd (Figures $4 \mathrm{~b}$ and $5 \mathrm{~b}$ ) pollutants.

The increase of photocatalytic efficiency for the sample Ti_FTO (58.3\% for Tr and 70.8\% for Apd) is related to the light conversion ability and charge carrier mobility of the heterostrucure. Considering that the photocatalytic process is dependent on the catalyst's conductivity, the heterostructure interface developed between $\mathrm{TiO}_{2}$ and $\mathrm{SnO}_{2}$ semiconductors made a significant contribution. The increase of charge carriers' mobility as well as their concentration would favor the formation of oxidative species [33] due to the additional contribution of the FTO conductive substrate (carrier mobility $13 \mathrm{~cm}^{2} / \mathrm{Vs}$ ). The sample Ti_Al, with efficiencies of $63.8 \%$ for $\operatorname{Tr}$ (scenario 7 ) and $82.3 \%$ for Apd (scenario 7), not only benefited from the substrate conductivity but also had the additional advantage of substrate reflectivity properties allowing multi-scattering [34]. The influence of total irradiance (Figures $4 \mathrm{c}$ and $5 \mathrm{c}$ ) after 4 and $8 \mathrm{~h}$ of irradiation was more evident when UV-A contributed for more than $50 \%$ of the total irradiance. On average, in the first $4 \mathrm{~h}, 70 \%$ of the photocatalytic degradation took place for $\operatorname{Tr}$ and $55 \%$ for Apd, showing that the reaction kinetics depended on the pollutant molecule. In the absence of UV-A radiation, the variation of the efficiency values after 4 and $8 \mathrm{~h}$ was small and did not justify the use of longer periods. 


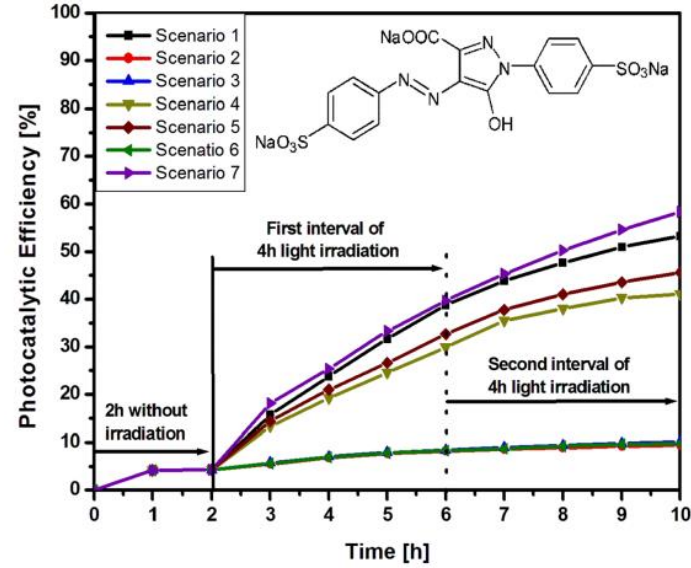

(a)

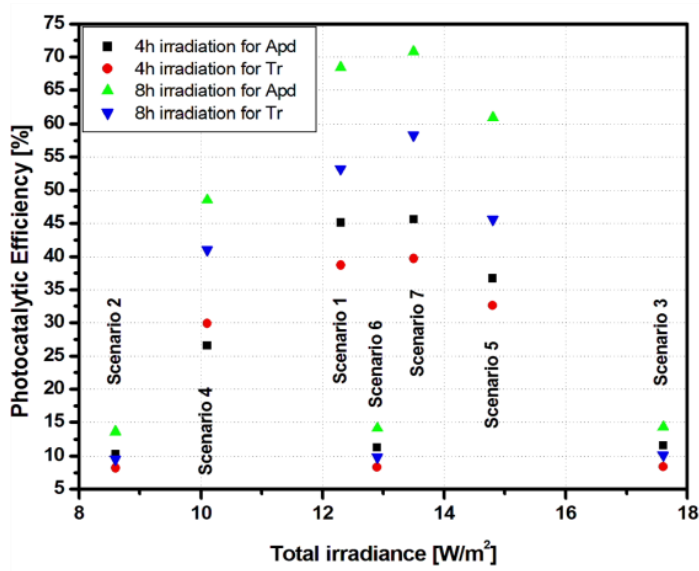

(c)

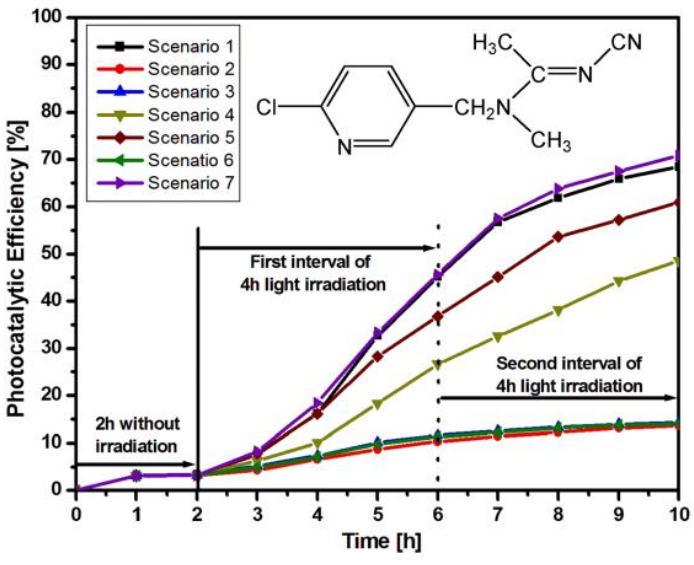

(b)

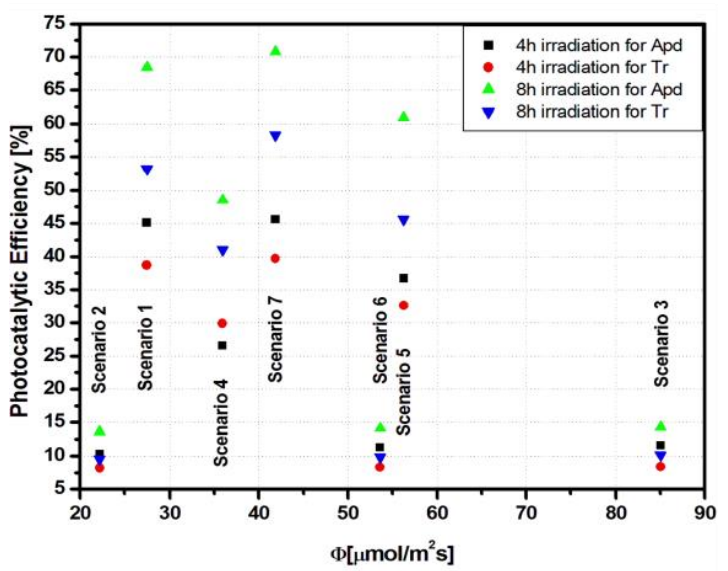

(d)

Figure 4. Photocatalytic parameters of the Ti_FTO sample: (a) Tr photodegradation, (b) Apd photodegradation, (c) total irradiance vs. photocatalytic efficiency, and (d) photon flux vs. photocatalytic efficiency.

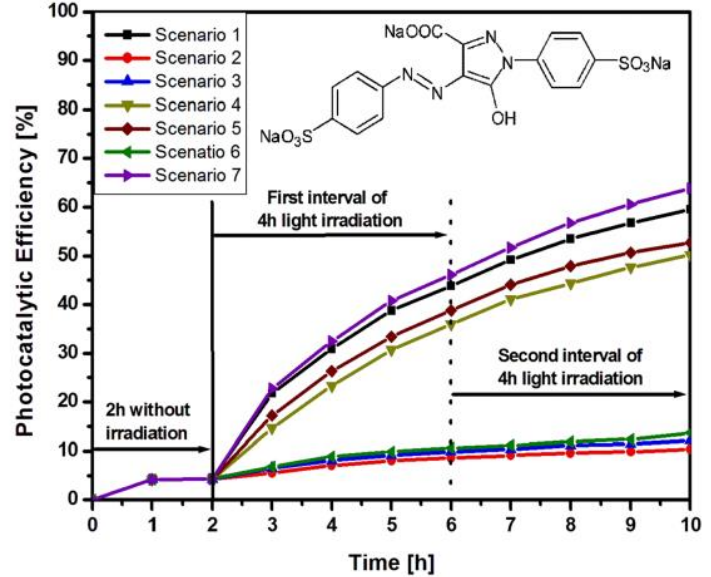

(a)

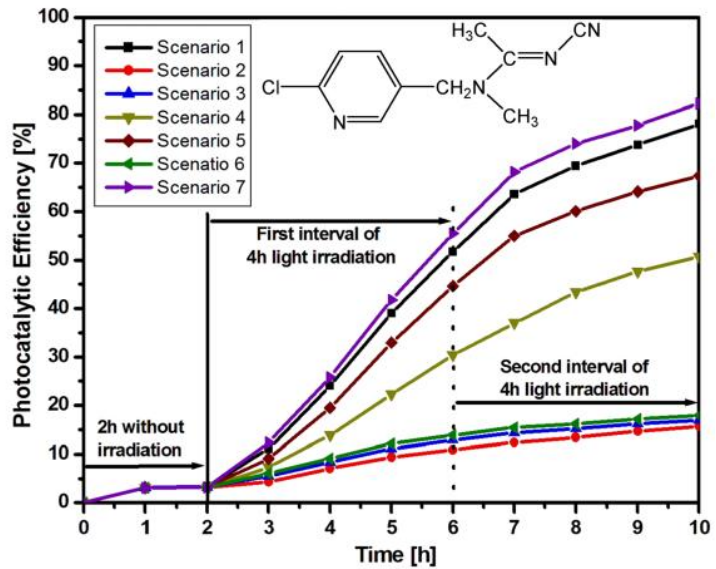

(b)

Figure 5. Cont. 


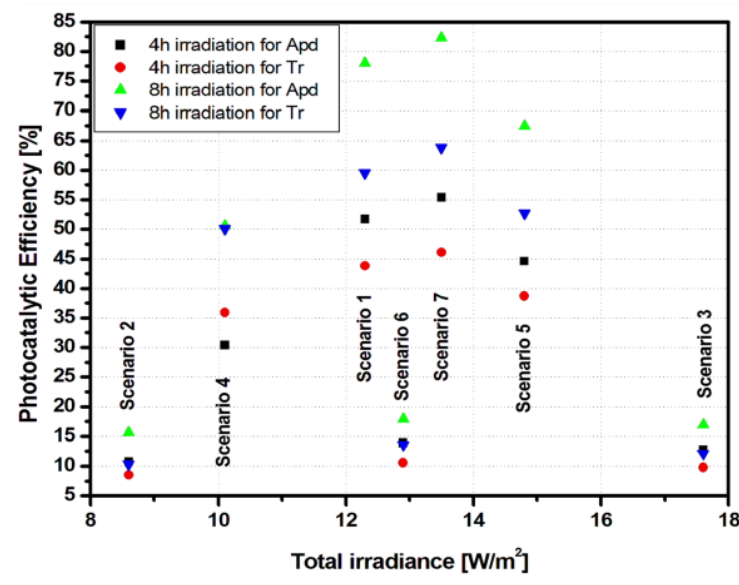

(c)

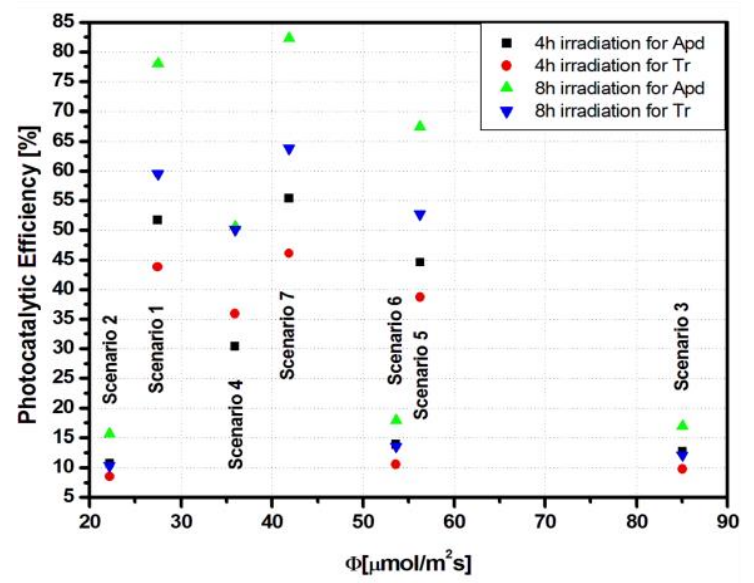

(d)

Figure 5. Photocatalytic parameters of the Ti_Al sample: (a) Tr photodegradation; (b) Apd photodegradation; (c) total irradiance vs. photocatalytic efficiency, and (d) photon flux vs. photocatalytic efficiency.

The photons flux had a similar influence on Ti_FTO (Figure 4d) and Ti_Al (Figure 5d) samples. However, it is important to underline that the highest efficiency (scenario 7) was obtain when the photon flux combined both UV-A and Vis sources, meaning that the catalyst was able to benefit from both radiation sources during the generation of superoxidative species (manly $\cdot \mathrm{O}_{2}{ }^{-}$and $\mathrm{HO}$. radicals). These results confirmed that the contribution of the photon flux to the photocatalytic process was correlated to the UV share of the overall radiation sources.

Further on, the effect of the radiation properties was correlated with the kinetic data, considering the simplified Langmuir-Hinshelwood (L-H) equation (Equation (3)), usually employed to describe, overall, a photocatalytic process:

$$
\ln C / C_{0}=-k t
$$

The kinetic evaluation of Ti_G photocatalytic properties (Figure 6) indicated the presence of two different intervals in the reaction pathway.

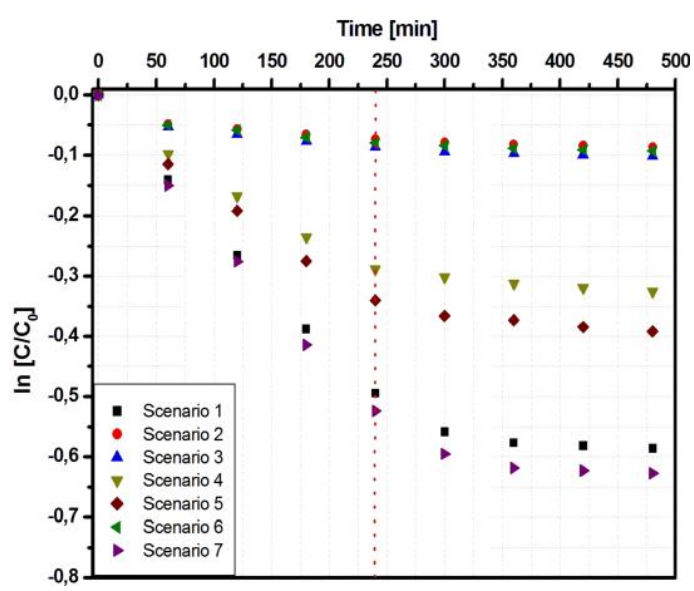

(a)

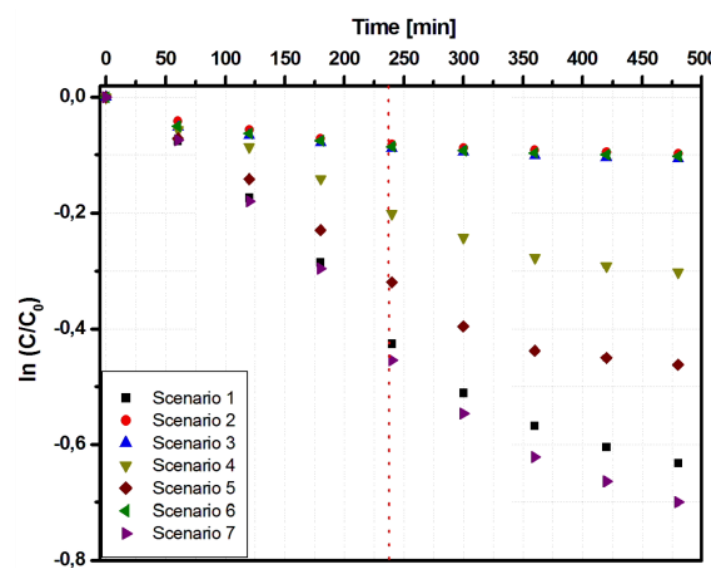

(b)

Figure 6. Kinetic data of the Ti_G sample using the Langmuir-Hinshelwood correlation: (a) Tr and (b) Apd photodegradation. 
The first interval (up to $240 \mathrm{~min}$ ) corresponded to the induction period [35], followed by fast pollutant (Tr and Apd) removal [36], with a contribution of almost $75 \%$ in the total process. The second interval (from 240 to $480 \mathrm{~min}$ ) showed a significant attenuation of the photocatalytic reaction rate, which can be attributed to surface inactivation due to the absorbance of the pollutant and the possible formation of by-products. In contrast, the samples deposed on conductive substrates such as Ti_FTO (Figure 7) and Ti_Al (Figure 8) presented a similar kinetic mechanism during the entire photocatalytic period. This result confirmed that the production of the oxidative species during the photocatalytic process was significantly influenced by the substrate nature [37].

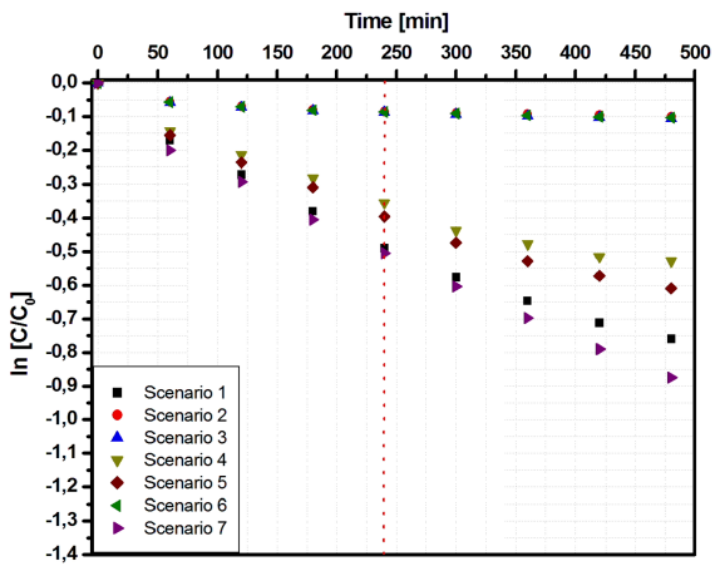

(a)

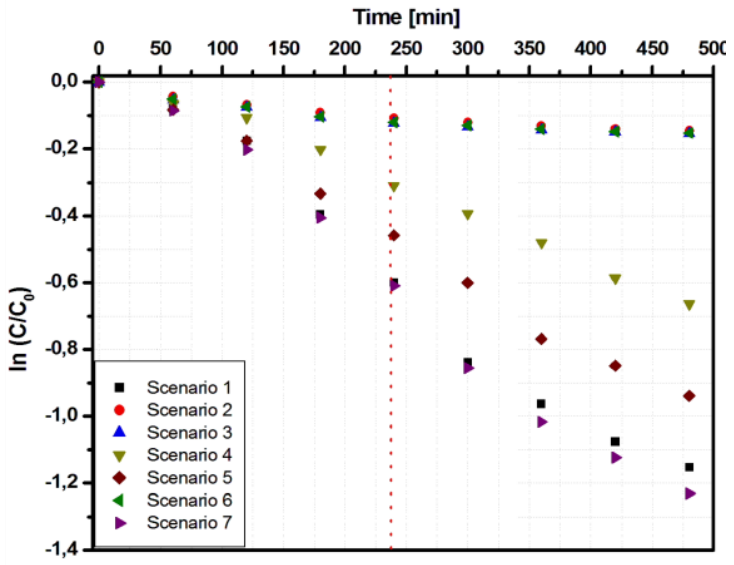

(b)

Figure 7. Kinetic data of the Ti_FTO sample using the Langmuir-Hinshelwood correlation: (a) Tr and (b) Apd photodegradation.

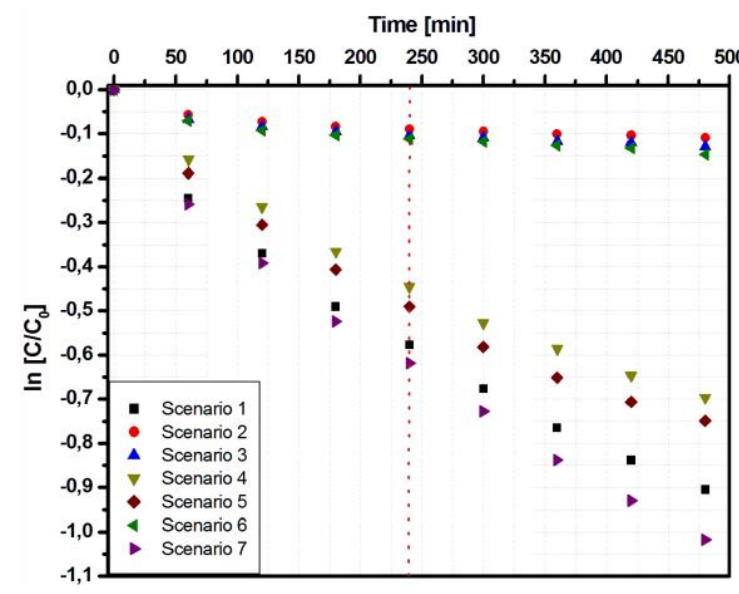

(a)

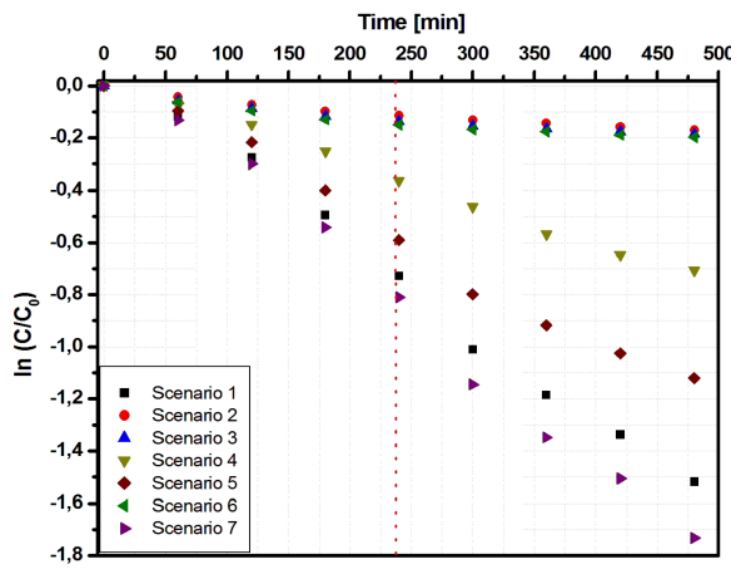

(b)

Figure 8. Kinetic data of the Ti_Al sample using the Langmuir-Hinshelwood correlation: (a) Tr and (b) Apd photodegradation.

The kinetic data model for these two-interval reaction are included in Table 3 for the Apd pollutant and Table 4 for the Tr pollutant. A closer look to the kinetic data indicates that a similar reaction rate for samples Ti_FTO and Ti_Al was measured only for the most suitable irradiation scenarios $(1,4$, 5 , and 7) in the case of Apd. In the other cases, the two-interval mechanism was more appropriate considering that the rate constants of the second interval were 3-4 times lower compared to those of the first interval. Another interesting finding is that the sample Ti_G exhibited a one-interval kinetic mechanism similar to Ti_FTO and Ti_Al only in the case of Apd removal using scenario 7. It was 
proven that scenario 7 allowed the higher photocatalytic efficiencies, but further investigations will be necessary to better understand this exception.

Table 3. Kinetic data for the Apd pollutant.

\begin{tabular}{|c|c|c|c|c|c|c|c|}
\hline \multirow{2}{*}{ Kinetic Data } & \multicolumn{7}{|c|}{ Irradiation Scenarios } \\
\hline & 1 & 2 & 3 & 4 & 5 & 6 & 7 \\
\hline \multicolumn{8}{|c|}{ Sample Ti_FTO } \\
\hline $\mathrm{k}_{0-240 \min }\left(\mathrm{s}^{-1}\right)$ & 0.00253 & 0.00044 & 0.00049 & 0.00126 & 0.00194 & 0.00048 & 0.00256 \\
\hline $\mathbf{R}^{2}{ }_{0-240 \min }$ & 0.9773 & 0.9834 & 0.9792 & 0.9854 & 0.9923 & 0.9816 & 0.9841 \\
\hline $\mathrm{k}_{240-480 \min }\left(\mathrm{s}^{-1}\right)$ & 0.00224 & 0.00015 & 0.00013 & 0.00125 & 0.00193 & 0.00013 & 0.00252 \\
\hline $\mathbf{R}^{2} 240-480$ & 0.9763 & 0.9918 & 0.9895 & 0.9990 & 0.9891 & 0.9858 & 0.9816 \\
\hline \multicolumn{8}{|c|}{ Sample Ti_G } \\
\hline $\mathrm{k}_{0-240 \min }\left(\mathrm{s}^{-1}\right)$ & 0.00177 & 0.00032 & 0.00034 & 0.00080 & 0.00133 & 0.00032 & 0.00188 \\
\hline $\mathbf{R}^{2}{ }_{0-240 \mathrm{~min}}$ & 0.9934 & 0.9576 & 0.9276 & 0.9948 & 0.9980 & 0.9295 & 0.9909 \\
\hline $\mathrm{k}_{240-480 \min }\left(\mathrm{s}^{-1}\right)$ & 0.00084 & 0.00006 & 0.00007 & 0.00041 & 0.00056 & 0.00006 & 0.00101 \\
\hline $\mathbf{R}^{2} 240-480$ & 0.9749 & 0.9863 & 0.9787 & 0.9640 & 0.9260 & 0.9796 & 0.9792 \\
\hline \multicolumn{8}{|c|}{ Sample Ti_Al } \\
\hline $\mathrm{k}_{0-240 \min }\left(\mathrm{s}^{-1}\right)$ & 0.00305 & 0.00047 & 0.00056 & 0.0015 & 0.00248 & 0.00061 & 0.00338 \\
\hline $\mathbf{R}^{2}{ }_{0-240 \min }$ & 0.9908 & 0.9848 & 0.9816 & 0.9955 & 0.9894 & 0.9802 & 0.9894 \\
\hline $\mathrm{k}_{240-480 \min }\left(\mathrm{s}^{-1}\right)$ & 0.00303 & 0.00023 & 0.00019 & 0.00146 & 0.00215 & 0.00019 & 0.00337 \\
\hline $\mathbf{R}^{2} 240-480$ & 0.9924 & 0.9981 & 0.9923 & 0.9942 & 0.9862 & 0.9915 & 0.9908 \\
\hline
\end{tabular}

Table 4. Kinetic data corresponding to the Tr pollutant.

\begin{tabular}{|c|c|c|c|c|c|c|c|}
\hline \multirow{2}{*}{ Kinetic Data } & \multicolumn{7}{|c|}{ Irradiation Scenarios } \\
\hline & 1 & 2 & 3 & 4 & 5 & 6 & 7 \\
\hline \multicolumn{8}{|c|}{ Sample Ti_FTO } \\
\hline $\mathrm{k}_{0-240 \min }\left(\mathrm{s}^{-1}\right)$ & 0.00198 & 0.00032 & 0.00033 & 0.00142 & 0.00157 & 0.00032 & 0.00202 \\
\hline $\mathbf{R}_{0-240 \min }^{2}$ & 0.9946 & 0.8915 & 0.8880 & 0.9859 & 0.9873 & 0.8897 & 0.9882 \\
\hline $\mathrm{k}_{240-480 \min }\left(\mathrm{s}^{-1}\right)$ & 0.00112 & 0.00005 & 0.00007 & 0.00070 & 0.00087 & 0.00007 & 0.00154 \\
\hline$R^{2} 240-480$ & 0.9945 & 0.9981 & 0.9951 & 0.9597 & 0.9882 & 0.9914 & 0.9997 \\
\hline \multicolumn{8}{|c|}{ Sample Ti_G } \\
\hline $\mathrm{k}_{0-240 \min }\left(\mathrm{s}^{-1}\right)$ & 0.00206 & 0.00027 & 0.00032 & 0.00119 & 0.00140 & 0.00030 & 0.00219 \\
\hline $\mathbf{R}_{0-240 \min }^{2}$ & 0.9988 & 0.8960 & 0.9175 & 0.9937 & 0.9949 & 0.9157 & 0.9987 \\
\hline$k_{240-480 \min }\left(s^{-1}\right)$ & 0.00034 & 0.00005 & 0.00006 & 0.00015 & 0.00020 & 0.00005 & 0.00039 \\
\hline $\mathbf{R}^{2} 240-480$ & 0.8609 & 0.9779 & 0.9564 & 0.9880 & 0.9647 & 0.9850 & 0.8646 \\
\hline \multicolumn{8}{|c|}{ Sample Ti_Al } \\
\hline $\mathrm{k}_{0-240 \min }\left(\mathrm{s}^{-1}\right)$ & 0.00233 & 0.00034 & 0.00039 & 0.00183 & 0.0020 & 0.00043 & 0.00250 \\
\hline$R_{0-240 \min }^{2}$ & 0.9791 & 0.9029 & 0.8964 & 0.9915 & 0.9863 & 0.9022 & 0.9808 \\
\hline $\mathrm{k}_{240-480 \min }\left(\mathrm{s}^{-1}\right)$ & 0.00136 & 0.00008 & 0.00010 & 0.00104 & 0.00107 & 0.00013 & 0.00167 \\
\hline $\mathbf{R}^{2} 240-480$ & 0.9965 & 0.9949 & 0.9917 & 0.9958 & 0.9890 & 0.9834 & 0.9985 \\
\hline
\end{tabular}

The two-interval kinetic mechanism was more obvious in Tr dye removal experiments, where all parameters indicated a high reaction rate in the first interval, which was significantly reduced in the second interval. These results are consistent with an increase of dye adsorption [38] on the catalyst surface, which may block some of the active sites responsible for the production of oxidative species. Due to his chemical nature, Tr dye molecules [39] have a high affinity for the $\mathrm{TiO}_{2}$ surface, exhibiting an amphoteric behavior [40] as a consequence of the ionization equilibrium $\left(\mathrm{OH}_{2}{ }^{+}, \mathrm{OH}^{-} \mathrm{O}^{-}\right)$.

The variation of these kinetic constants with the photon flux for Tr (Figure 9a) and Apd (Figure 9b) was investigated. The results indicated that the two-interval mechanism was characterized by a low reaction rate and no significant influence of the photon flux. The kinetic mechanism may be attributed to extended adsorption, which is agreement with the papers published by Somma et al. [41] and Zhao et al. [42], showing that the reduction of the photocatalytic reaction rate corresponds to the partial degradation of the pollutant, forming hydroxylated intermediates [43]. 

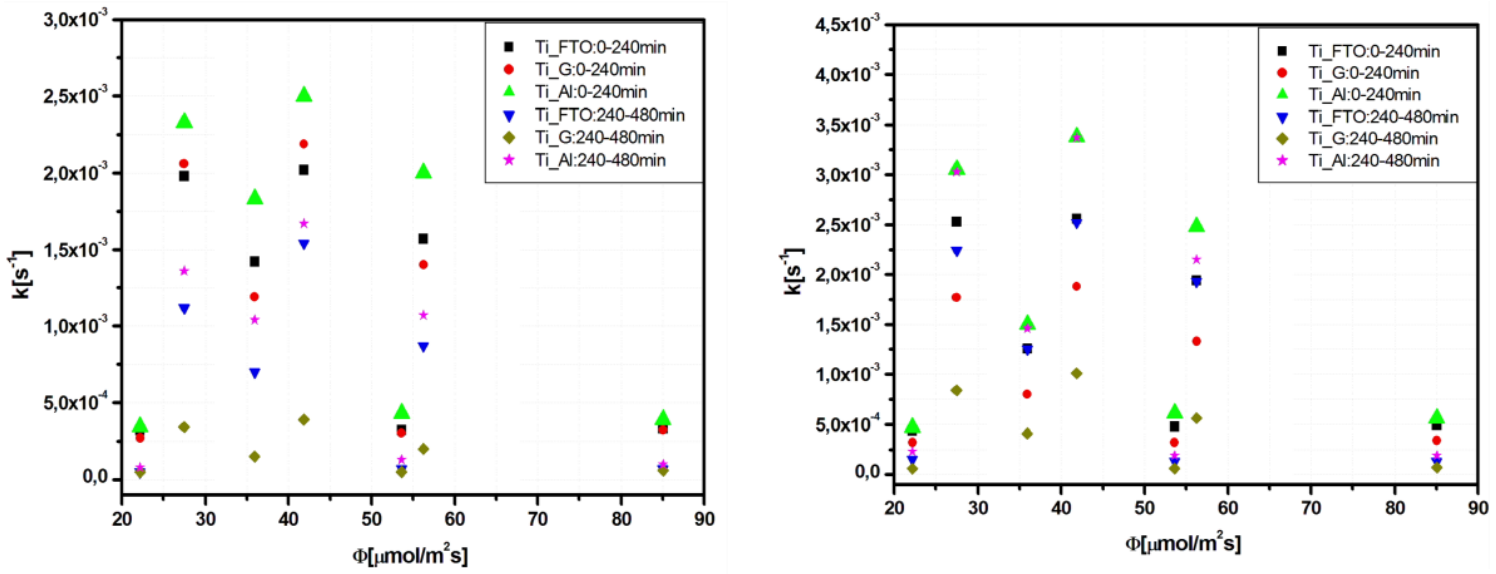

Figure 9. Variation of the rate constants with photon flux for (a) Tr and (b) Apd photodegradation.

Some of these intermediates can follow the degradation pathway towards mineralization, while others may remain unchanged. However, the photon flux has a rather negligible effect on the kinetic constants in the absence of UV-A radiation. These results underline the significance of optimizing the radiation source ratio in order to influence the kinetic mechanism of photocatalytic processes.

The L-H model as proposed by Turchi and Ollis [44] was further used to model the effect of photon absorption using only scenario 7 for all samples:

$$
r=-\frac{d C}{d t}=\frac{k_{r} K_{S} C}{1+K_{S} C^{\prime}}
$$

where $r$ is the photocatalytic degradation rate $\left(\mathrm{mol} \cdot \mathrm{L}^{-1} \cdot \mathrm{min}^{-1}\right), C$ represent the TR and Apd concentration $\left(\mathrm{mol} \cdot \mathrm{L}^{-1}\right), \mathrm{k}_{\mathrm{r}}$ is the apparent reaction rate constant $\left(\mathrm{mol} \cdot \mathrm{L}^{-1} \cdot \mathrm{min}^{-1}\right.$ ), and $K_{s}$ represent the apparent adsorption constant $\left(\mathrm{L} \cdot \mathrm{mol}^{-1}\right)$. The term $k_{r} \cdot K_{s}$ is globally evaluated as an apparent rate constant $\mathrm{k}\left(\mathrm{min}^{-1}\right)$. The $k_{r}$ constant considers the photon flux; consequently, Equation (4) can be modified as follows:

$$
\frac{1}{r}=\frac{1}{k_{r} K_{S}} \times \frac{1}{C}+\frac{1}{k_{r}}
$$

On a linear plot of $1 / r$ vs. $1 / C$, the intercept $\left(1 / k_{r}\right)$ and the slope $\left(1 / k_{r} K_{S}\right)$ allow calculating the kinetic parameters. The values corresponding to scenario 7 are included in Table 5.

\begin{tabular}{|c|c|c|c|c|}
\hline Sample, Pollutant & 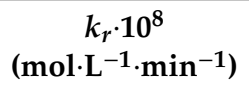 & $K_{\mathrm{s}}\left(\mathrm{mol} \cdot \mathrm{L}^{-1}\right)$ & $k \cdot\left(\min ^{-1}\right)$ & $\mathbf{R}^{2}$ \\
\hline Ti_G, Tr & 1.33 & 47243.5 & 0.000628 & 0.9386 \\
\hline Ti_G, Apd & 1.58 & 54473.8 & 0.000838 & 0.9854 \\
\hline Ti_FTO, Tr & 1.74 & 617562.4 & 0.001074 & 0.9942 \\
\hline Ti_FTO, Apd & 2.81 & 967867.9 & 0.002719 & 0.9930 \\
\hline Ti_Al, Tr & 2.00 & 709424.9 & 0.001418 & 0.9875 \\
\hline Ti_Al, Apd & 3.82 & 131114.3 & 0.005008 & 0.9955 \\
\hline
\end{tabular}

Table 5. Kinetic parameters based on Equation (4) for irradiation scenario 7.

The results indicate that the L-H equation supports the experimental data for samples Ti_FTO and Ti_Al. In these two cases, the apparent reaction rates showed the same order of magnitude of the apparent adsorption constant, while for the Ti_G sample, there was a difference corresponding to one order of magnitude. Consequently, it is feasible to conclude that when using a conductive substrate for catalyst deposition, the degradation mechanism is less affected by the radiation intensity than when using non-conductive substrates. This conclusion was also reached by Andronic et al. [45], 
who showed that using conductive substrates will favor the mobility of the charge carriers and the conversion to oxidative species during photocatalytic processes.

\section{Conclusions}

The influence of radiation sources, total irradiance, and photon flux on the photocatalytic removal of the dye Tr and the pesticide Apd was investigated. Titanium oxide (Degussa P25)-based films containing both anatase and rutile structures were deposed by the doctor blade technique using three types of substrate: a non-conductive substrate (microscopic glass) and two conductive (FTO and aluminum) substrates.

The presence of a conductive substrate and a suitable ratio of UV-A and Vis radiations increased the samples' photocatalytic efficiency. The highest efficiencies were obtained for Ti_FTO (58.3\% for Tr and $70.8 \%$ for Apd) and Ti_Al (63.8\% for Tr and $82.3 \%$ for Apd) samples using a mixture of three UV-A and one Vis sources $\left(13.5 \mathrm{~W} / \mathrm{m}^{2}\right.$ and $\left.41.85 \mu \mathrm{mol} /\left(\mathrm{m}^{2} \cdot \mathrm{s}\right)\right)$. A kinetic evaluation showed the presence of two different mechanisms of reaction, depending on irradiation time exposure and irradiation scenarios.

These results indicate that in order to optimize the design of photocatalytic processes, it is important to adjust the photon flux and the irradiation sources to the catalyst substrate and pollutant type. The use of conductive substrates compatible with the photocatalyst morphology will have a positive impact on the photocatalytic efficiency, improving the charge carrier's mobility and the development of oxidative species. Increasing the radiation intensity can be economically non-feasible, considering that the photocatalytic processes are not characterized by a linear efficiency-irradiation evolution.

Author Contributions: Conceptualization, A.E.; methodology, L.I.; validation, A.E. and L.I.; formal analysis, A.E.; investigation, L.I.; resources, L.I.; data curation, A.E.; writing-original draft preparation, A.E.; writing-review and editing, L.I.; visualization, L.I.; supervision, A.E.; project administration, A.E.; funding acquisition, A.E. All authors have read and agreed to the published version of the manuscript.

Funding: This research was funded by CNCSIS, through the PED project "Hybrid and composite photocatalytic structures for indoor air and wastewater decontamination".

Conflicts of Interest: The authors declare no conflict of interest. The funders had no role in the design of the study; in the collection, analyses, or interpretation of data; in the writing of the manuscript, or in the decision to publish the results.

\section{References}

1. Rueda-Marquez, J.J.; Levchuk, I.; Ibañez, P.F.; Sillanpää, M. A critical review on application of photocatalysis for toxicity reduction of real wastewaters. J. Clean. Prod. 2020, 25810, 120694. [CrossRef]

2. Duta, A.; Andronic, L.; Enesca, A. The influence of low irradiance and electrolytes on the mineralization efficiency of organic pollutants using the Vis-active photocatalytic tandem CuInS $2 / \mathrm{TiO}_{2} / \mathrm{SnO}_{2}$. Catal. Today 2018, 3001, 18-27. [CrossRef]

3. Ma, D.; Li, J.; Liu, A.; Chen, C. Carbon Gels-Modified $\mathrm{TiO}_{2}$ : Promising Materials for Photocatalysis Applications. Materials 2020, 13, 1734. [CrossRef] [PubMed]

4. Kanagamani, K.; Muthukrishnan, P.; Saravanakumar, K.; Shankar, K.; Kathiresan, A. Photocatalytic degradation of environmental perilous gentian violet dye using leucaena-mediated zinc oxide nanoparticles and its anticancer activity. Rare Met. 2019, 38, 277-286. [CrossRef]

5. Youssef, Z.; Colombeau, L.; Yesmurzayeva, N.; Baros, F.; Acherar, S. Dye-sensitized nanoparticles for heterogeneous photocatalysis: Cases studies with $\mathrm{TiO}_{2}, \mathrm{ZnO}$, fullerene and graphene for water purification. Dyes Pigm. 2018, 159, 49-71. [CrossRef]

6. Calvo, H.; Redondo, D.; Remón, S.; Venturini, M.E.; Arias, E. Efficacy of electrolyzed water, chlorine dioxide and photocatalysis for disinfection and removal of pesticide residues from stone fruit. Postharvest Biol. Technol. 2019, 148, 22-31. [CrossRef]

7. Marien, C.B.D.; Le Pivert, M.; Azaïs, A.; M’Bra, I.C.; Robert, D. Kinetics and mechanism of Paraquat's degradation: UV-C photolysis vs UV-C photocatalysis with $\mathrm{TiO}_{2} / \mathrm{SiC}$ foams. J. Hazard. Mater. 2019, 37015, 164-171. [CrossRef] 
8. Talwar, S.; Sangal, V.K.; Verma, A. Feasibility of using combined $\mathrm{TiO}_{2}$ photocatalysis and $\mathrm{RBC}$ process for the treatment of real pharmaceutical wastewater. J. Photochem. Photobiol. A 2018, 35315, 263-270. [CrossRef]

9. Díez, A.M.; Moreira, F.C.; Marinho, B.A.; Espíndola, J.C.A.; Vilar, V.J.P. A step forward in heterogeneous photocatalysis: Process intensification by using a static mixer as catalyst support. Chem. Eng. J. 2018, 3431, 597-606. [CrossRef]

10. Enesca, A.; Yuichi, Y.; Chiaki, T.; Fujishima, A.; Nakata, K.; Duta, A. Enhanced UV-Vis photocatalytic performance of the $\mathrm{CuInS}_{2} / \mathrm{TiO}_{2} / \mathrm{SnO}_{2}$ hetero-structure for air decontamination. J. Catal. 2017, 350, 174-181. [CrossRef]

11. Dosa, M.; Piumetti, M.; Bensaid, S.; Andana, T.; Galletti, C.; Fino, D.; Russo, N. Photocatalytic Abatement of Volatile Organic Compounds by $\mathrm{TiO}_{2}$ Nanoparticles Doped with Either Phosphorous or Zirconium. Materials 2019, 12, 2121. [CrossRef] [PubMed]

12. Park, D.; Shahbaz, H.M.; Kim, S.H.; Lee, M.; Park, J. Inactivation efficiency and mechanism of UV-TiO 2 photocatalysis against murine norovirus using a solidified agar matrix. Int. J. Food Microbiol. 2016, 2385, 256-264. [CrossRef] [PubMed]

13. Yang, Y.; Yang, J.; Cao, J.; Wang, Z. Pretreatment with concurrent UV photocatalysis and alkaline $\mathrm{H}_{2} \mathrm{O}_{2}$ enhanced the enzymatic hydrolysis of sisal waste. Bioresour. Technol. 2018, 267, 517-523. [CrossRef] [PubMed]

14. Ran, J.; Chen, H.; Bai, X.; Bi, S.; Wang, X. Immobilizing $\mathrm{CuO} / \mathrm{BiVO}_{4}$ nanocomposite on PDA-templated cotton fabric for visible light photocatalysis, antimicrobial activity and UV protection. Appl. Surf. Sci. 2019, 4931, 1167-1176. [CrossRef]

15. Andronic, L.; Enesca, A.; Cazan, C.; Visa, M. $\mathrm{TiO}_{2}$-active carbon composites for wastewater photocatalysis. J. Sol Gel Sci. Technol. 2014, 71, 396-405. [CrossRef]

16. Wang, X.; Wang, X.; Zhao, J.; Song, J.; Wang, Z. Adsorption-photocatalysis functional expanded graphite C/C composite for in-situ photocatalytic inactivation of Microcystis aeruginosa. Chem. Eng. J. 2018, 3411, 516-525. [CrossRef]

17. Yang, Y.; Tang, Y.; Jiang, H.; Chen, Y.; Wan, P.; Fan, M.; Zhang, R.; Ullah, S.; Pan, L.; Zou, J.J.; et al. 2020 Roadmap on gas-involved photo- and electro-catalysis. Chin. Chem. Lett. 2019, 30, 2089-2099. [CrossRef]

18. Dudita, M.; Bogatu, C.; Enesca, A.; Duta, A. The influence of the additives composition and concentration on the properties of $\mathrm{SnO}_{x}$ thin films used in photocatalysis. Mater. Lett. 2011, 65, 2185-2189. [CrossRef]

19. Sacco, O.; Sannino, D.; Matarangolo, M.; Vaiano, V. Room Temperature Synthesis of V-Doped $\mathrm{TiO}_{2}$ and Its Photocatalytic Activity in the Removal of Caffeine under UV Irradiation. Materials 2019, 12, 911. [CrossRef]

20. Manisha, H.; Priya Swetha, P.D.; Shim, Y.B.; Prasad, K.S. Microwave Assisted Synthesis of Hybrid $\mathrm{Cu}_{2} \mathrm{O}$ Microcubes for Photocatalysis and Electrocatalysis. Mater. Today Proc. 2018, 5, 16390-16393. [CrossRef]

21. Enesca, A.; Andronic, L.; Duta, A. The influence of surfactants on the crystalline structure, electrical and photocatalytic properties of hybrid multi-structured $\left(\mathrm{SnO}_{2}, \mathrm{TiO}_{2}\right.$ and $\left.\mathrm{WO}_{3}\right)$ thin films. Appl. Surf. Sci. 2012, 258, 4339-4346. [CrossRef]

22. Sharma, K.; Dutta, V.; Sharma, S.; Raizada, P.; Singh, P. Recent advances in enhanced photocatalytic activity of bismuth oxyhalides for efficient photocatalysis of organic pollutants in water: A review. J. Ind. Eng. Chem. 2019, 7825, 1-20. [CrossRef]

23. Sharifi, A.; Montazerghaem, L.; Naeimi, A.; Abhari, A.R.; Sadegh, H. Investigation of photocatalytic behavior of modified ZnS:Mn/MWCNTs nanocomposite for organic pollutants effective photodegradation. J. Environ. Manag. 2019, 2471, 624-632. [CrossRef] [PubMed]

24. Scanlon, D.O.; Dunnill, C.W.; Buckeridge, J.; Shevlin, S.A.; Logsdail, A.J.; Woodley, S.M.; Richard, C.; Catlow, A.; Powell, M.J.; Palgrave, R.G.; et al. Band alignment of rutile and anatase $\mathrm{TiO}_{2}$. Nat. Mater. 2013, 12, 798-801. [CrossRef]

25. Fittipaldi, M.; Gatteschi, D.; Fornasiero, P. The power of EPR techniques in revealing active sites in heterogeneous photocatalysis: The case of anion doped $\mathrm{TiO}_{2}$. Catal. Today 2013, 2061, 2-11. [CrossRef]

26. Hu, J.; Li, J.; Cui, J.; An, W.; Cui, W. Surface oxygen vacancies enriched FeOOH/Bi $2 \mathrm{MoO}_{6}$ photocatalysis-fenton synergy degradation of organic pollutants. J. Hazard. Mater. 2020, 38415, 121399. [CrossRef]

27. Huang, Y.; Bai, J.; Zhou, G.; Bi, S.; Seo, H.J. Co-precipitation synthesis, band modulation and improved visible-light-driven photocatalysis of $\mathrm{Te}^{4+} / \mathrm{Ti}^{4+}$-codoped $\mathrm{Bi}_{3} \mathrm{Nb}_{17} \mathrm{O}_{47}$. Ceram. Int. 2020, 46, 7131-7141. [CrossRef]

28. Wei, G.; Basheer, C.; Tan, C.H.; Jiang, Z. Visible light photocatalysis in chemoselective functionalization of C $\left(\mathrm{sp}^{3}\right) \mathrm{H}$ bonds enabled by organic dyes. Tetrahedron Lett. 2016, 57, 3801-3809. [CrossRef] 
29. Enesca, A.; Andronic, L.; Duta, A. Optimization of Opto-Electrical and Photocatalytic Properties of $\mathrm{SnO}_{2}$ Thin Films Using $\mathrm{Zn}^{2+}$ and $\mathrm{W}^{6+}$ Dopant Ions. Catal. Lett. 2012, 142, 224-230. [CrossRef]

30. Wen, C.; Yin, A.; Dai, W.L. Recent advances in silver-based heterogeneous catalysts for green chemistry processes. Appl. Catal. B 2014, 160-161, 730-741. [CrossRef]

31. Fischer, K.; Gläser, R.; Schulze, A. Nanoneedle and nanotubular titanium dioxide-PES mixed matrix membrane for photocatalysis. Appl. Catal. B 2014, 160-161, 456-464. [CrossRef]

32. Colón, G. Towards the hydrogen production by photocatalysis. Appl. Catal. A 2016, 518, 48-59. [CrossRef]

33. Diaz-Angulo, J.; Porras, J.; Mueses, M.; Torres-Palma, R.A.; Machuca-Martinez, F. Coupling of heterogeneous photocatalysis and photosensitized oxidation for diclofenac degradation: Role of the oxidant species. J. Photochem. Photobiol. A 2019, 3831, 112015. [CrossRef]

34. Xie, B.W.; Dong, J.; Zhao, J.M.; Liu, L.H. Radiative properties of hedgehog-like ZnO-Au composite particles with applications to photocatalysis. J. Quant. Spectrosc. Radiat. Transf. 2018, 217, 1-12. [CrossRef]

35. He, L.; Liu, C.; Tang, J.; Zhou, Y.; Hu, J. Self-catalytic stabilized Ag-Cu nanoparticles with tailored SERS response for plasmonic photocatalysis. Appl. Surf. Sci. 2018, 43415, 265-272. [CrossRef]

36. Shavisi, Y.; Sharifnia, S.; Mohamadi, Z. Solar-light-harvesting degradation of aqueous ammonia by CuO/ZnO immobilized on pottery plate: Linear kinetic modeling for adsorption and photocatalysis process. J. Environ. Chem. Eng. 2016, 4, 2736-2744. [CrossRef]

37. Sun, Z.; Zhang, X.; Zhu, R.; Dong, X.; Xu, J.; Wang, B. Facile Synthesis of Visible Light-Induced g- $\mathrm{C}_{3} \mathrm{~N}_{4}$ /Rectorite Composite for Efficient Photodegradation of Ciprofloxacin. Materials 2018, 11, 2452. [CrossRef]

38. Wang, S.; Guan, Y.; Wang, L.; Zhao, W.; Sun, C. Fabrication of a novel bifunctional material of BiOI/Ag $\mathrm{AgO}_{4}$ with high adsorption-photocatalysis for efficient treatment of dye wastewater. Appl. Catal. B 2015, 168-169, 448-457. [CrossRef]

39. Khanna, A.; Shetty, V.K. Solar light induced photocatalytic degradation of Reactive Blue 220 (RB-220) dye with highly efficient $\mathrm{Ag} @ \mathrm{TiO}_{2}$ core-shell nanoparticles: A comparison with UV photocatalysis. Sol. Energy 2014, 99, 67-76. [CrossRef]

40. Kondrakov, A.O.; Ignatev, A.N.; Frimmel, F.H.; Bräse, S.; Revelsky, A.I. Formation of genotoxic quinones during bisphenol A degradation by $\mathrm{TiO}_{2}$ photocatalysis and UV photolysis: A comparative study. Appl. Catal. B 2014, 160-161, 106-114. [CrossRef]

41. Di Somma, I.; Clarizia, L.; Satyro, S.; Spasiano, D.; Andreozzi, R. A kinetic study of the simultaneous removal of EDDS and cupric ions from acidic aqueous solutions by $\mathrm{TiO}_{2}$-based photocatalysis under artificial solar light irradiation and deaerated batch conditions. Chem. Eng. J. 2015, 27015, 519-527. [CrossRef]

42. Zhao, C.; Pelaez, M.; Dionysiou, D.D.; Pillai, S.C.; O'Shea, K.E. UV and visible light activated $\mathrm{TiO}_{2}$ photocatalysis of 6-hydroxymethyl uracil, a model compound for the potent cyanotoxin cylindrospermopsin. Catal. Today 2014, 2241, 70-76. [CrossRef]

43. Huang, Y.; Li, H.; Fan, W.; Zhao, F.; Qiu, W.; Ji, H.; Tong, Y. Defect Engineering of Bismuth Oxyiodide by $\mathrm{IO}_{3}{ }^{-}$ Doping for Increasing Charge Transport in Photocatalysis. ACS Appl. Mater. Interfaces 2016, 8, 27859-27867. [CrossRef] [PubMed]

44. Duta, A.; Enesca, A.; Bogatu, C.; Gyorgy, E. Solar-active photocatalytic tandems. A compromise in the photocatalytic processes design. Mater. Sci. Semicond. Proc. 2016, 42, 94-97. [CrossRef]

45. Andronic, L.; Hristache, B.; Enesca, A.; Visa, M.; Duta, A. Studies on titanium oxide catalyst doped with heavy metals (cadmium, copper and nikel). Environ. Eng. Manag. J. 2009, 8, 747-751. [CrossRef]

(C) 2020 by the authors. Licensee MDPI, Basel, Switzerland. This article is an open access article distributed under the terms and conditions of the Creative Commons Attribution (CC BY) license (http://creativecommons.org/licenses/by/4.0/). 